UNDERGROUND MINING ENGINEERING 31 (2017) 77-83 $\quad$ UDK 62

\title{
STANDARD DEVIATIONS OF COORDINATES DUE TRANSFORMATION
} BETWEEN ELLIPSOIDS

\author{
Aleksandar Ganić ${ }^{1}$, Aleksandar Milutinović1 ${ }^{1}$ Zoran Gojković ${ }^{1}$
}

Received: October 7, 2017

Accepted: November 19, 2017

\begin{abstract}
Transformation between ellipsoids also called datum transformation implies coordinate conversion from one ellipsoid to another ellipsoid, most frequently to be done by Helmert seven-parameter transformation. Transformation parameters involve three rotation, three translation and scale factor and they can be calculated using reference points which are known before and after transformation. Transformation parameters can be obtained with appropriate measurements and in accoradance with measurement uncertainties, they are produce errors of transformed coordinates. This paper describes standard errors of transformed coordinates using Helmert seven-parameter transformation, when switching from ellipsoid WGS84 to Bessel ellipsoid.
\end{abstract}

Keywords: geodetic datum; Helmert seven-parameter transformation; coordinates;

\section{INTRODUCTION}

The physical surface of the earth has irregular shape which is not mathematically defined, therefore the shape of the Earth is approximated with mathematically defined surfaces such as ellipsoid and sphere. Dimensions and relationship between rotational ellipsoid and Earth is called geodetic datum. In the Republic of Serbia, until January 1, 2011 had been applied geodetic datum MGI 1901 established during Austro-Hungarian monarchy with Bessel 1841 reference ellipsoid (Wikipedia, 2016). This can be seen as local geodetic datum.

From January, 12011 and onwards, in the Republic of Serbia for reference system is applied three dimensional coordinate system who matches with the European Terrestrial Reference System 1989 (ETRS 89), by definition of the coordinate origin, coordinate axis orientation, scale, the unit of length and time evolution (Ganić et al., 2012). For mathematical model of the Earth in the Republic of Serbia is adopted referential twoaxis rotational ellipsoid called Geodetic Reference System 1980 (GRS 80), and this can be seen as global geodetic datum.

\footnotetext{
${ }^{1}$ University of Belgrade - Faculty of Mining and Geology, Đušina 7, 11000 Belgrade, Serbia emails:aleksandar.ganic@ rgf.bg.ac.rs, aleksandar.milutinovic@ rgf.bg.ac.rs, zoran.gojkovic@ @rgf.bg.ac.rs
} 
Satellite geodesy, i.e. Global Positioning System (GPS) has become more and more represented in the realization of various geodetic tasks. Data, i.e. coordinates of the points which are determined by GPS observations define position of the points on rotational ellipsoid called World Geodetic System 1984 (WGS 84) which is slightly different from the GRS 80 ellipsoid (semi-major axis are equal and deference between semi-minor axis is $0.105 \mathrm{~mm}$ ) (Wikipedia, 2017). With GPS observations are determined rectangular coordinates $\mathrm{X}, \mathrm{Y}, \mathrm{Z}$ which are referred to three-dimensional rectangular coordinate system. Coordinate center of this system coincidence with ellipsoid center, i.e. center of the Earth (global datum is geocentric), whereby the $\mathrm{X}$-axis lies within the plane of Equator and it is normal to intersection point between the Equator and Greenwich meridian, the $\mathrm{Y}$-axis lies within the Equator plane and it is normal to $\mathrm{X}$-axis and the $\mathrm{Z}$-axis is oriented towards the mean axis of rotation of the Earth. For the purpose of the further application, these rectangular coordinates are transformed into curvilinear coordinates such as geodetic (ellipsoidal) longitude $L$, geodetic (ellipsoidal) latitude $B$ and ellipsoidal height $h$ (Figure 1) (Jovanović, 1983). In the further, curvilinear coordinates are transformed in the plane of the conformal Universal Transverse Mercator (UTM) projection which represent new state projection in the Republic of Serbia, i.e. new state coordinate system in the horizontal plane.

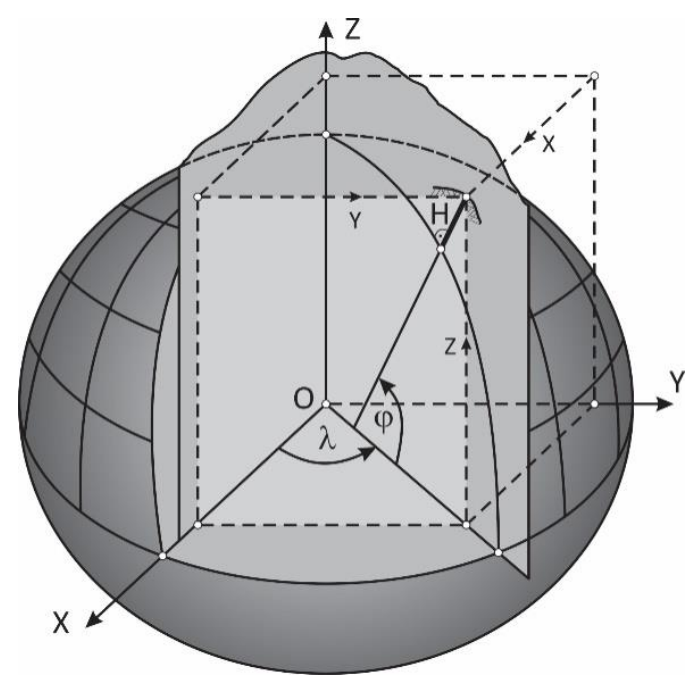

Figure 1 Rectangular and curvilinear coordinates 


\section{DATUM TRANSFORMATION AND ERRORS OF THE TRANSFORMED COORDINATES}

Law obligation in the realization of the geodetic tasksis that coordinates of the points in the horizontal plane need to be expressed in relation to the new state coordinate system. However, in the cadastral municiplities where the new coordinate system has not ben implemented are still in use coordinates expressed into Gauss-Kruger projection. Also, some Investors still require informations about points into Gauss-Kruger coordinate system which is related for Bessel rotational ellipsoid.

Datum tranformation of the coordinates between new state coordinate system and GaussKruger coordinate system is determined by Helmert seven-parameter transformations and correction from grid rezidual that are uniquely determined for teritory of the Republic of Serbia.

Seven-parameter transformation consists three translations of the coordinate center by axes $t_{x}, t_{y}, t_{z}$, three rotations of the coordinate axes $\varepsilon_{x}, \varepsilon_{y}, \varepsilon_{z}$ and change in the scale $s$ (Figure 2). The datum transformation is performed at the level of the rectangular coordiantes $X, Y, Z$. Equation of the seven-parameter transformation in the matrix form is given as (Bašić, 2017; Gojković et al. 2017):

$$
\left[\begin{array}{c}
X_{B e s} \\
Y_{\text {Bes }} \\
Z_{\text {Bes }}
\end{array}\right]=(1+s) \cdot\left[\begin{array}{ccc}
1 & +\varepsilon_{z} & -\varepsilon_{y} \\
-\varepsilon_{z} & 1 & +\varepsilon_{x} \\
+\varepsilon_{y} & -\varepsilon_{x} & 1
\end{array}\right] \cdot\left[\begin{array}{c}
X_{W G S} \\
Y_{W G S} \\
Z_{W G S}
\end{array}\right]+\left[\begin{array}{c}
t_{x} \\
t_{y} \\
t_{z}
\end{array}\right]
$$

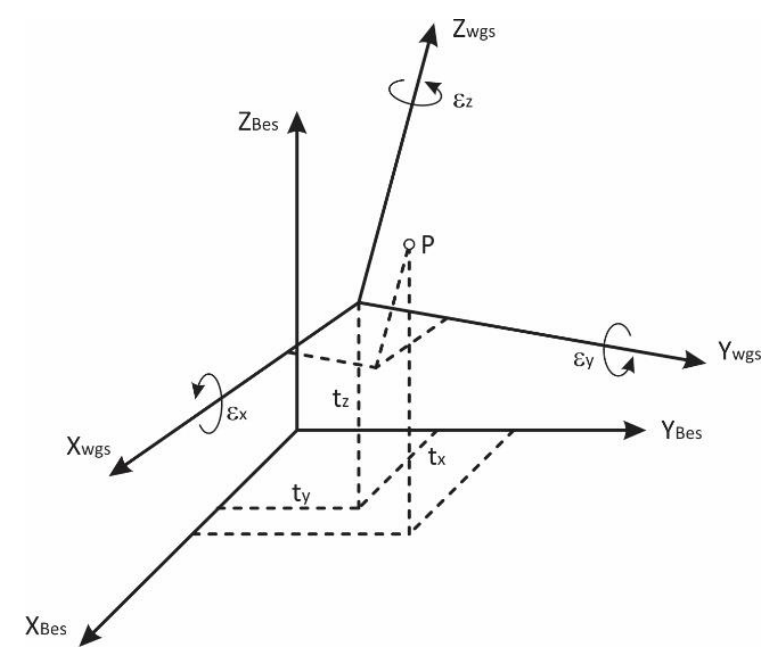

Figure 2 Helmert's seven-parameter transformation 
In the Republic of Serbia, global transformations parameters are determined by 1217 points of state trigonometric network. Parameters are determined with standard errors shown in the table 1 (Republički geodetski zavod, 2017).

Table 1 Global transformation parameters with standard deviations

\begin{tabular}{ccc}
\hline & Parameters & Standard deviation \\
\hline \multirow{4}{*}{ Translation } & $t_{x}=+574.02732 \mathrm{~m}$ & $\sigma_{t_{x}}=0.015 \mathrm{~m}$ \\
& $t_{y}=+170.17492 \mathrm{~m}$ & $\sigma_{t_{y}}=0.015 \mathrm{~m}$ \\
& $t_{z}=+401.54530 \mathrm{~m}$ & $\sigma_{t_{z}}=0.015 \mathrm{~m}$ \\
\hline \multirow{3}{*}{ Rotation } & $\varepsilon_{x}=-4.88786^{\prime \prime}$ & $\sigma_{\varepsilon_{x}}=0.032^{\prime \prime}$ \\
& $\varepsilon_{y}=+0.66524^{\prime \prime}$ & $\sigma_{\varepsilon_{y}}=0.049^{\prime \prime}$ \\
& $\varepsilon_{z}=+13.24673^{\prime \prime}$ & $\sigma_{\varepsilon_{z}}=0.044^{\prime \prime}$ \\
\hline Scale & $s=+6.88933 \mathrm{ppm}$ & $\sigma_{s}=0.106 \mathrm{ppm}$ \\
\hline
\end{tabular}

Considering error propagation law, it is of the important interest to know how parameters errors affect on the accuracy of the transformed coordinates, i.e. what are values of the errors of the transformed coordinates considering standard errors of the parameters.

For that cause, matrix equation of the seven parameter transformation (1) are shown as follows:

$$
\begin{aligned}
& X_{B e s}=(1+s) \cdot X_{W G S}+(1+s) \cdot \varepsilon_{z} \cdot Y_{W G S}-(1+s) \cdot \varepsilon_{y} \cdot Z_{W G S}+t_{x} \\
& Y_{B e s}=-(1+s) \cdot \varepsilon_{z} \cdot X_{W G S}+(1+s) \cdot Y_{W G S}+(1+s) \cdot \varepsilon_{x} \cdot Z_{W G S}+t_{y} \\
& Z_{B e s}=(1+s) \cdot \varepsilon_{y} \cdot X_{W G S}-(1+s) \cdot \varepsilon_{x} \cdot Y_{W G S}+(1+s) \cdot Z_{W G S}+t_{z}
\end{aligned}
$$


Considering error propagation law, for equations (2) need to be determined partial derivatives by transformation parameters, shown below:

$$
\begin{array}{lll}
\frac{\partial X_{B e s}}{\partial s}=X_{W G S}+\varepsilon_{z} \cdot Y_{W G S}-\varepsilon_{y} \cdot Z_{W G S} ; & \frac{\partial Y_{B e s}}{\partial s}=-\varepsilon_{z} \cdot X_{W G S}+Y_{W G S}+\varepsilon_{x} \cdot Z_{W G S} ; & \frac{\partial Z_{B e s}}{\partial s}=\varepsilon_{y} \cdot X_{W G S}-\varepsilon_{x} \cdot Y_{W G S}+Z_{W G S} ; \\
\frac{\partial X_{B e s}}{\partial \varepsilon_{z}}=(1+s) \cdot Y_{W G S} ; & \frac{\partial Y_{B e s}}{\partial \varepsilon_{z}}=-(1+s) \cdot X_{W G S} ; & \frac{\partial Z_{B e s}}{\partial \varepsilon_{y}}=(1+s) \cdot X_{W G S} ; \\
\frac{\partial X_{B e s}}{\partial \varepsilon_{y}}=-(1+s) \cdot Z_{W G S} ; & \frac{\partial Y_{B e s}}{\partial \varepsilon_{x}}=(1+s) \cdot Z_{W G S} ; & \frac{\partial Z_{B e s}}{\partial \varepsilon_{x}}=-(1+s) \cdot Y_{W G S} \\
\frac{\partial X_{B e s}}{\partial t t_{x}}=+1 ; & \frac{\partial Y_{B e s}}{\partial t_{y}}=+1 ; & \frac{\partial Z_{B e s}}{\partial t_{z}}=+1
\end{array}
$$

Standard errors of the transformed coordinates, considering standard deviations of the transformation parameters are calculated by using the following equations:

$$
\begin{aligned}
& \sigma_{X_{B e s}}=\sqrt{\left(\frac{\partial X_{B e s}}{\partial s}\right)^{2} \cdot \sigma_{s}^{2}+\left(\frac{\partial X_{B e s}}{\partial \varepsilon_{z}}\right)^{2} \cdot\left(\frac{\sigma_{\varepsilon_{z}}^{\prime \prime}}{\rho^{\prime \prime}}\right)^{2}+\left(\frac{\partial X_{B e s}}{\partial \varepsilon_{y}}\right)^{2} \cdot\left(\frac{\sigma_{\varepsilon_{y}}^{\prime \prime}}{\rho^{\prime \prime}}\right)^{2}+\left(\frac{\partial X_{B e s}}{\partial t_{x}}\right)^{2} \cdot \sigma_{t_{x}}{ }^{2}} \\
& \sigma_{Y_{\text {Bess }}}=\sqrt{\left(\frac{\partial Y_{B e s}}{\partial s}\right)^{2} \cdot \sigma_{s}^{2}+\left(\frac{\partial Y_{B e s}}{\partial \varepsilon_{z}}\right)^{2} \cdot\left(\frac{\sigma_{\varepsilon_{z}}^{\prime \prime}}{\rho^{\prime \prime}}\right)^{2}+\left(\frac{\partial Y_{B e s}}{\partial \varepsilon_{x}}\right)^{2} \cdot\left(\frac{\sigma_{\varepsilon_{x}}^{\prime \prime}}{\rho^{\prime \prime}}\right)^{2}+\left(\frac{\partial Y_{B e s}}{\partial t_{y}}\right)^{2} \cdot \sigma_{t_{y}}{ }^{2}} \\
& \sigma_{Z_{B e s}}=\sqrt{\left(\frac{\partial Z_{B e s}}{\partial s}\right)^{2} \cdot \sigma_{s}{ }^{2}+\left(\frac{\partial Z_{B e s}}{\partial \varepsilon_{y}}\right)^{2} \cdot\left(\frac{\sigma_{\varepsilon_{y}}^{\prime \prime}}{\rho^{\prime \prime}}\right)^{2}+\left(\frac{\partial Z_{B e s}}{\partial \varepsilon_{x}}\right)^{2} \cdot\left(\frac{\sigma_{\varepsilon_{x}}^{\prime \prime}}{\rho^{\prime \prime}}\right)^{2}+\left(\frac{\partial Z_{B e s}}{\partial t_{z}}\right)^{2} \cdot \sigma_{t_{z}}{ }^{2}}
\end{aligned}
$$

Where values of the standard errors of the angles are given in the radians $\left(\rho^{\prime \prime}=206265^{\prime \prime}\right)$.

\section{EXAMPLE}

Standard deviations of the coordinates are calculated for point located near building of the faculty for Mining and Geology University in Belgrade. Rectangular spatial coordinates are:

$$
X_{W G S}=4245960.149 \mathrm{~m} ; Y_{W G S}=1585245.324 \mathrm{~m} ; Z_{W G S}=4472803.986 \mathrm{~m}
$$

According to the equations (3), calculated partial derivatives by transformation parameters are shown below: 


$$
\begin{array}{lll}
\frac{\partial X_{\text {Bes }}}{\partial s}=4245501.716 \mathrm{~m} & \frac{\partial Y_{\text {Bes }}}{\partial s}=1585773.854 \mathrm{~m} & \frac{\partial Z_{\text {Bes }}}{\partial s}=4473090.907 \mathrm{~m} \\
\frac{\partial X_{B e s}}{\partial \varepsilon_{z}}=1585384.272 \mathrm{~m} & \frac{\partial Y_{\text {Bes }}}{\partial \varepsilon_{z}}=-4245559.858 \mathrm{~m} & \frac{\partial Z_{\text {Bes }}}{\partial \varepsilon_{y}}=4245559.858 \mathrm{~m} \\
\frac{\partial X_{\text {Bes }}}{\partial \varepsilon_{y}}=-4473111.352 \mathrm{~m} & \frac{\partial Y_{\text {Bes }}}{\partial \varepsilon_{x}}=4473111.352 \mathrm{~m} & \frac{\partial Z_{\text {Bes }}}{\partial \varepsilon_{x}}=-1585384.272 \mathrm{~m} \\
\frac{\partial X_{\text {Bes }}}{\partial t_{x}}=+1 & \frac{\partial Y_{\text {Bes }}}{\partial t_{y}}=+1 & \frac{\partial Z_{\text {Bes }}}{\partial t_{z}}=+1
\end{array}
$$

Standard deviations of the transformed coordinates onto Bessel's ellipsoid, according to the equations (4) are:

$$
\sigma_{X_{\text {Bes }}}=1.203 \mathrm{~m} ; \quad \sigma_{Y_{\text {Bes }}}=1.153 \mathrm{~m} ; \quad \sigma_{Z_{\text {Bes }}}=1.141 \mathrm{~m}
$$

\section{CONCLUSION}

Datum transformation carried out using Helmert's seven-parameter transformation allows transition from one reference elipsoid to another and vice versa. However, transformed coordinates on this way are within metric accuracy.On the territory of the Republic of Serbia, the standard errors of the transformed coordinates are in the range of $1.176 \mathrm{~m}<\sigma_{X}<1.216 \mathrm{~m} ; 1.149 \mathrm{~m}<\sigma_{Y}<1.162 \mathrm{~m} ; 1.126 \mathrm{~m}<\sigma_{Z}<1.170 \mathrm{~m}$. Therefore, the transformed coordinates of the geodetic points can not be used for state survey works or for cadastral tasks, and especially for tasks where higher accuracy of data are required. The only right thing for realization geodetic tasks using GPS technology is to be used AGROS network of permanent stations or points which belong to Serbian Referent Frame (SREF) network with expression of the coordinates in the horizontal plane in Universal traverse Mercator projection.

\section{REFERENCES}

BAŠIĆ, T. (2017) Primjena u praksi T7D modela transformacije. [Online] Sveučilište u Zagrebu - Geodetski fakultet. Available from: http://www.geof.unizg.hr/pluginfile .php/5622/mod resource/content/Primjena\%20u\%20praksi\%20T7D 17022017r.pdf [Accessed 08/30/2017].

GANIĆ, A., MILUTINOVIĆ, A., and TRIFUNOVIĆ, P. (2012) The new state reference system of the republic of Serbia and division into map and layout series. Podzemni Radovi, 21, pp.177-191. 
GOJKOVIĆ, Z., RADOJIČIĆ, M., and VULOVIĆ, N. (2017) Application for coordinate transformation between Gauss - Kruger projection - Bessel ellipsoid and UTM projection WGS84 ellipsoid. Podzemni Radovi, 30, pp.29-45.

JOVANOVIĆ, V. (1983) Matematička kartografija. Beograd: Vojnogeografski institut.

REPUBLIČKI GEODETSKI ZAVOD (2017). Available from: http://www.rgz.gov .rs/template1.asp?PageName=2005 12_26_1\&MenuID=none\&LanguageID $=2$ [Accessed $08 / 22 / 2017]$.

WIKIPEDIA (2016). Bessel ellipsoid. [Online]. Available from: https://en.wikipedia .org/wiki/Bessel_ellipsoid [Accessed 10/14/2017].

Wikipedia (2017). World Geodetic Sytem. [Online]. Available from: https://en. wikipedia.org/wiki/World_Geodetic_System\#WGS84 [Accessed 10/14/2017]. 